\title{
New Mycomya species from South Korea (Diptera: Mycetophilidae)
}

\author{
Rauno Väisänen
}

\begin{abstract}
Väisänen, R. 2013: New Mycomya species from South Korea (Diptera: Mycetophilidae). - Entomol. Fennica 24: 165-171.

The material of the genus Mycomya Rondani from South Korea is revised. The following three new species are described: M. yamagishii sp. n., M. mogera sp. n., and M. sudosanensis sp. n. Mycomya winnertzi (Dziedzicki), M. dziedzickii Väisänen, M. occultans (Winnertz), M. wuorentausi Väisänen, and M. paradentata Väisänen are recorded as new to the South Korean fauna. A key is given to the South Korean species.
\end{abstract}

R. Väisänen, Metsähallitus Natural Heritage Services, P. O. Box 94, FI-01301, Vantaa, Finland; E-mail: rauno.vaisanen@metsa.fi

Received 1 June 2012, accepted 22 November 2012

\section{Introduction}

The taxonomy of the mycetophilid genus Mycomya Rondani, 1856 is relatively wellknown in the western Palaearctic region (Väisänen 1984a), but during the last three decades increasing information has become available also from the eastern Palaeactic region. Several Mycomya species have been recorded and described from China (e.g. Wu \& Yang 1990, 1992, 1994a, b, 1995a, b, 1996, Wu 1995, 1998, Wu et al. 2001) and eastern Russia (Väisänen 1984a, Zaitzev 1994, Krzeminska \& Klimont 2011). There are also scattered records of Mycomya species from other areas in eastern and southeastern Asia (e.g. Edwards 1935, Shinji 1939, Okada 1940, Sasakawa 1961, 2003, 2005, Colless \& Liepa 1973, Laštovka \& Matile 1974, Väisänen 1984a, b, 1996).

This paper is the first contribution to the Mycomya species of the Korean peninsula. Three new species from South Korea are described below, and five other species are recorded as new to the South Korean fauna. Keys to the subgenera and the Holarctic species were provided by Väisänen (1984a). A key is given here to the South Korean species. Mycomya species are usually readily recognizable on the basis of the male hypopygium (terminalia), while external characters are relatively unreliable as diagnostic characters.

\section{Material and methods}

The study material comes from the Kyushu University Collections, Biosystematics Laboratory, Ropponmatsu, Fukuoka, Japan (KUC). The material was collected on Mount Sudo-san in the south-eastern part of South Korea.

The methodology and morphological terminology in the main follows that of Väisänen (1984a, 1996). Leg ratios refer to the length ratio of each basitarsus and the respective tibia. The wing vein ratios ( $\mathrm{M}$ and $\mathrm{Cu}$ ratios) were calculated as follows: first, the length ratio of the petiole to the anterior branch (M1 or Cul) and second, the length ratio of the petiole to the posterior branch (M2 or $\mathrm{Cu} 2)$. 


\section{Key to South Korean Mycomya species}

1. Coxa 2 with a spur

- Coxa 2 without a spur

6 (Subgenus Mycomyopsis)

2. Abdominal tergites entirely dark or light, or dark with paler posterior margins; abdominal tergite 8 with setae; tergite 9 without a forklike median structure; ocellar prominence not distinctly darker than posterior parts of head; spur of coxa 2 long, more than half of the length of coxa 3 (Subgenus Mycomya p.p.)

- Abdominal tergites yellow with dark posterior margins; abdominal tergite 8 bare; tergite 9 with a fork-like median structure; ocellar prominence usually distinctly darker than posterior parts of head; spur of coxa 2 short, less than half of the length of coxa

5 (Subgenus Calomycomya)

3. Processus of tergite 9 short, wide, apically more or less bilobed

- Processus of tergite 9 long, slender, not bilobed M. occultans (Winnertz)

4. Processus apically only slightly bilobed; inner margin of tergal lateral appendage densely covered with short setae

M. winnertzi (Dziedzicki)

- Processus deeply bilobed; tergal lateral appendage with some scattered

M. dziedzickii Väisänen

5. Tergal fork of tergite 9 basally Y-shaped; gonostylus with a long, slender branch and a short, slender, curved branch

M. yamagishii sp. $\mathbf{n}$.

- Tergal fork of tergite 9 basally V-shaped; gonostylus with a long, wide, apically curved branch and a short, slender, curved branch

\section{M. wuorentausi Väisänen}

6. Sternal submedian filament missing

\section{M. mogera sp. n.}

- Sternal submedian filament present

\section{7}

7. Tergal lateral appendage of tergite 9 wide with a very wide comb-like brush of flattened, apical-subapical setae covering almost half of its inner margin; base of tergite 9 without a basal extension; gonostylus with 2 teeth

M. paradentata Väisänen

- Tergal lateral appendage slender with dense group of flattened, curved apical setae; base of tergite 9 with a long curved lateral extension; gonostylus with 5-6 teeth

M. sudosanensis n. sp.

\section{The species}

\subsection{Subgenus Mycomya s. str.}

\subsubsection{Mycomya winnertzi (Dziedzicki, 1885)}

Material examined. 1 male: South Korea, Gyongsangbug-Do, Mt. Sudo-san, 800 m, 5.VIII.1977, K. Yamagishi leg. (in KUC).

Distribution. The South Korean specimen belongs to the nominal subspecies, not to $M$. winnertzi schmidi Väisänen, 1984 known from the Himalayas (Väisänen 1984a, 1996). Widely distributed in the Holarctic region (Väisänen 1984a), new to the South Korean fauna. Reported from Japan (Shinji 1939, Okada 1940). For its biology, see Väisänen (1984a).

\subsubsection{Mycomya dziedzickii Väisänen, 1981}

Material examined. 1 male: South Korea, Gyongsangbug-Do, Mt. Sudo-san, 800 m, 5.VIII.1977, K. Yamagishi leg. (in KUC).

Distribution. Previously known only from Western Palaearctic region (Väisänen 1984a, Zaitzev 1994). For its biology, see Väisänen (1984a).

\subsubsection{Mycomya occultans (Winnertz, 1863)}

Material examined. 1 male: South Korea, Gyongsangbug-Do, Mt. Sudo-san, 1,000 m, 1.VIII. 1977, K. Yamagishi leg. (in KUC); 1 male, same data, 800 m, 5.VIII.1977 (in KUC).

Distribution. Widely distributed in the Palaearctic region (Väisänen 1984a). Recorded from the Kuril Islands (Väisänen 1984a), Japan (Sasakawa 1961, Väisänen 1984b), China (Shanxi, Zhejiang, Guizhou) (Wu \& Yang 1994a, Wu 1995), India (Uttar Pradesh) and Myanmar (Väisänen 1996). For its biology, see Väisänen (1984a) and Jakovlev (2011). 
Fig. 1. Mycomya yamagishii sp. n., male hypopygium. - a-b. Tergal and sternal views. -c. Apex of sternal lateral appendage, twice enlarged. - d. Gonostylus, twice enlarged. $-\mathrm{e}$. Apex of aedeagus, lateral view, twice enlarged. Scale bar 0.2 $\mathrm{mm}$.

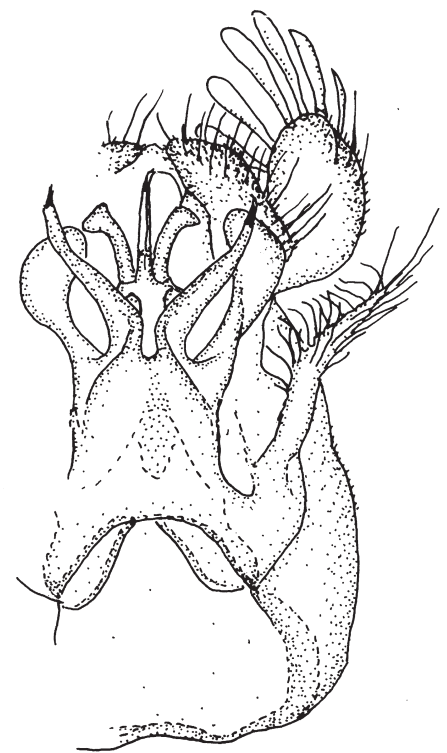

a

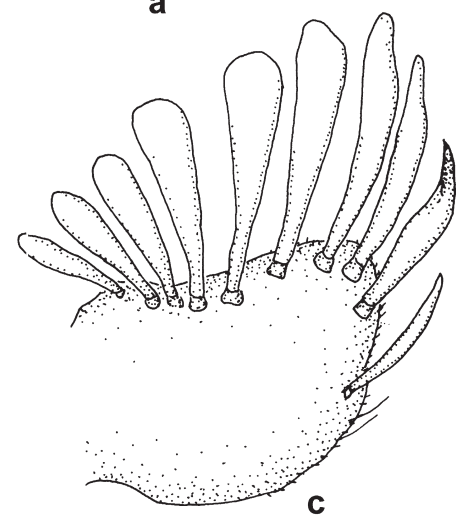

\subsection{Subgenus Calomycomya Väisänen, 1984}

\subsubsection{Mycomya yamagishii sp. n. (Fig. 1)}

Type material. Holotype male: South Korea, Gyongsangbug-Do, Mt. Sudo-san, 500 m, 8.VI. 1977, K. Yamagishi leg. (in KUC).

Description. Male.

Head. Palp, other mouthparts and face yellow, posterior parts of head yellowish, ocellar prominence brown. Antenna brownish, scape, pedicel and base of 1 st flagellomere yellow. $1^{\text {st }}$ flagellomere about $3 \times, 2^{\text {nd }} 1.5 \times$ as long as wide.

Thorax. Pronotum yellow, with 5 longer setae. Mesoscutum yellow with 3 brownish undistinct longitudinal stripes. Mesanepisternum and mesokatepisternum yellow. Scutellum yel- b
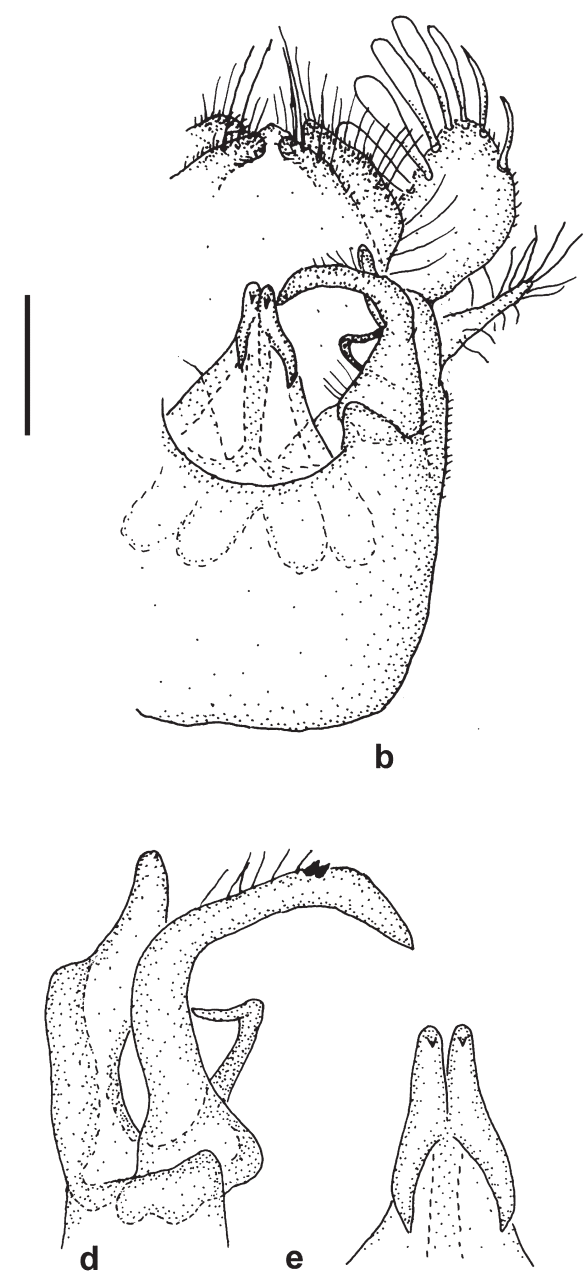

lowish, with 4 long setae. Laterotergite yellow. Mediotergite yellowish, bare.

Wing. Length $4.2 \mathrm{~mm}$. Hyaline, apex very weakly infuscated. Sc ending in C distally to middle of small cell, Sc2 ending in R1distally to middle of small cell. Apical part of Sc bearing 20 macrotrichia. Small cell about twice as long as wide. $\mathrm{Cu}$ fork below $\mathrm{M}$ fork. M ratios: 0.45, 0.60. $\mathrm{Cu}$ ratios: $0.77,1.15$. Macrotrichia: $\mathrm{M}$ petiole: 0 ; M1: +; M2: +; Cu petiole: +; Cu1: +; Cu2: +. Halter pale yellowish.

Legs. Coxae and femora yellow, tibiae and tarsi brownish to brown. Coxa 1 with some thin setae along anteromedial surface. Coxa 2 with short curved spur with 1 apical teeth. Leg ratios: $\mathrm{bt} 1: \mathrm{t} 1=$ ?, bt2:t2 = ?, bt $3: \mathrm{t} 3=$ ?

Abdomen. Tergites 1-5 yellow, with brown 


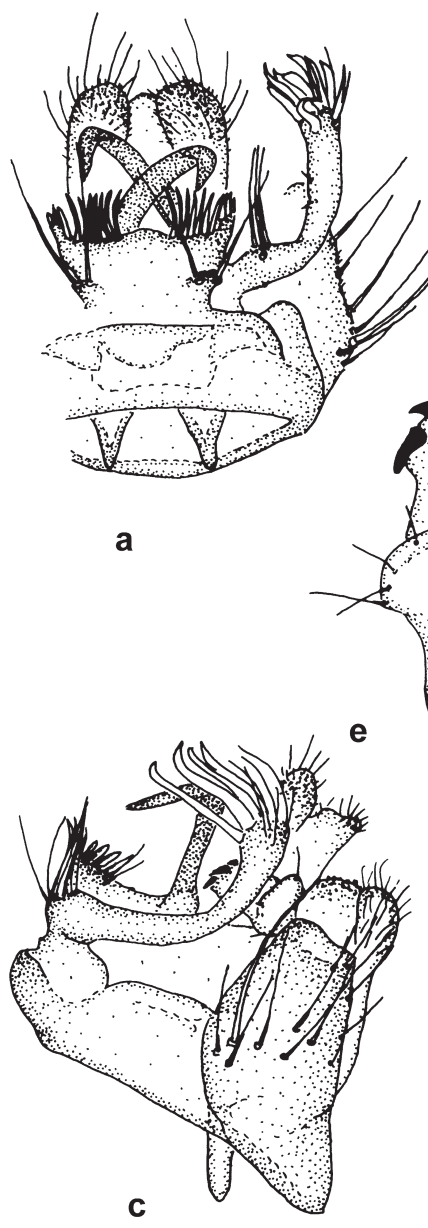

C
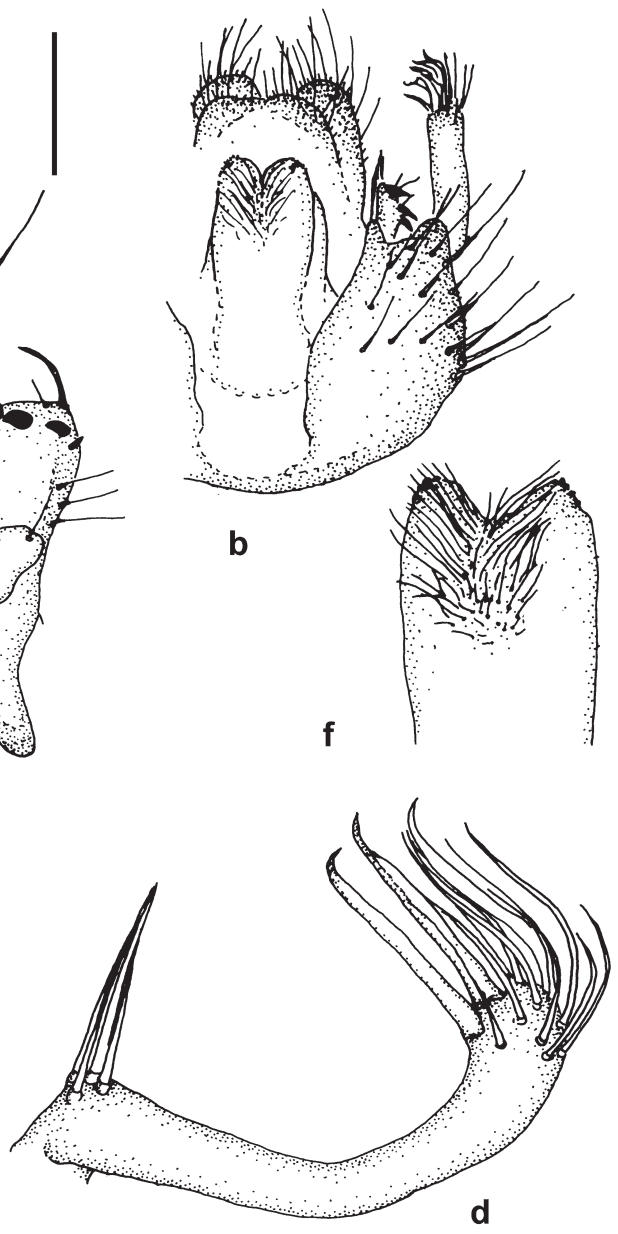

Fig. 2. Mycomya mogera sp. n., male hypopygium. - a-c. Tergal, sternal and lateral views. - d. Tergal lateral appendage, twice enlarged. - e. Gonostylus, twice enlarged. $-f$. Apex of aedeagus, sternal view, twice enlarged. Scale bar 0.2 $\mathrm{mm}$.

medial line and posterior margins, 6-7 brownish to brown. Sternites 1-5 yellow, 6-7 brownish.

Hypopygium (Fig. 1). Yellowish. Tergal fork Y-shaped, deeply bilobed, with short apical setae and rounded lateral lobes. Sternal lateral appendage with many flattened setae (Fig. 1c). Gonostylus with two branches, one long and curved with two subapical teeth, and another short, slender and curved (Fig. 1d). Aedeagus with 2 long spurs (Fig. 1e).

Female. Unknown.

Distribution. South Korea.

Etymology. The species is named after the Japanese entomologist K. Yamagishi, who collected the holotype.

Remarks. Differs from the other species of the subgenus Calomycomya (see Väisänen 1984a, and M. lintanana in Wu \& Yang 1994b) in the de- tails of the male hypopygium, e.g. the characteristic shapes of the tergal fork and the gonostylus.

\subsubsection{Mycomya wuorentausi Väisänen, 1984}

Material examined. 2 males: South Korea, Gyongsangbug-Do, Mt. Sudo-san, 1,000 m, 1.VIII.1977, K. Yamagishi leg. (in KUC).

Distribution: Described from Vladivostok, Russian Far East (Väisänen 1984a). Recorded also from Zhejiang and Fujian in China (Wu \& Yang 1994a) and Japan (Sasakawa 2005).

\subsection{Subgenus Mycomyopsis Väisänen, 1984}

\subsubsection{Mycomya mogera sp. n. (Fig. 2)}

Type material. Holotype male: South Korea, 
Gyongsangbug-Do, Mt. Sudo-san, 1,000 m, 1.VIII.1977, K. Yamagishi leg. (in KUC). Paratypes: same data, 31 males (in KUC).

\section{Description. Male.}

Head. Palp, other mouthparts and face yellow, posterior parts of head brownish to brown. Antenna brownish, scape, pedicel and base of $1^{\text {st }}$ flagellomere yellow. $1^{\text {st }}$ flagellomere about $4 \times, 2^{\text {nd }}$ $2.5 \times$ as long as wide.

Thorax. Pronotum yellow, with 3-4 longer setae. Mesoscutum yellow with 3 brown fused longitudinal stripes. Mesanepisternum and mesokatepisternum yellow. Scutellum yellow, with 4 long setae. Laterotergite yellow. Mediotergite yellowish, bare.

Wing. Length 3.5-4.0 mm. Hyaline. Sc ending in R1 slightly distally or proximally to middle of small cell, Sc1 missing. Apical part of Sc bearing 1-11 macrotrichia. Small cell about 1.5 times as long as wide. $\mathrm{Cu}$ fork distinctly distal to $\mathrm{M}$ fork. $\mathrm{M}$ ratios: $0.96-1.05,1.38-1.44 . \mathrm{Cu}$ ratios: 0.96-1.04, 1.56-1.60. Macrotrichia: M petiole: 0; M1: 0; M2: 0; $\mathrm{Cu}$ petiole: 0; $\mathrm{Cu} 1: 0 ; \mathrm{Cu} 2: 0$. Halter pale yellowish.

Legs. Coxae and femora yellow, tibiae and tarsi brownish to brown. Coxa 1 without special setae. Coxa 2 without spur. Leg ratios: bt1:t1 = $0.83-0.88$, bt $2: \mathrm{t} 2=0.71, \mathrm{bt} 3: \mathrm{t} 3=0.58-0.61$.

Abdomen. Tergites brownish, sternites yellowish.

Hypopygium (Fig. 2). Yellow. Tergite 9 with two pairs of combs, outer combs clearly separated from each other, both with 6-7 spines. Tergal lateral appendage long, slender and slightly curved, with pale curved apical setae, middle part bare, and a spine-like group of basal setae (Fig. 2d). Sternal submedian filament missing. Gonostylus with 4-5 small subapical teeth and a long seta (Fig. 2e). Apex of aedeagus wide, setose (Fig. 2f).

Female. Unknown.

Distribution. South Korea.

Etymology. The species name is an arbitrary combination of letters.

Remarks. Differs from the other species of the subgenus Mycomyopsis in the details of the male hypopygium, e.g. the shape and setosity of tergal lateral appendage and the lack of sternal submedian filaments. Chinese M. elegantula, $\mathrm{Wu}$ \& Yang, 1992, differs from M. mogera $\mathbf{s p .}$. in having short sternal submedian appendage and tergal lateral appendages without flattened apical setae.

\subsubsection{Mycomya paradentata Väisänen, 1984}

Material examined. 2 males: South Korea, Gyongsangbug-Do, Mt. Sudo-san, 1,000 m, 1.VIII.1977, K. Yamagishi leg., (in KUC).

Distribution. Previously known only from Western Paleaerctic region: France, Poland, Denmark, Sweden, Finland, Russia (near St. Petersburg) and Ukraine.

\subsubsection{Mycomya sudosanensis sp. n. (Fig. 3)}

Type material. Holotype male: South Korea, Gyonsangbug-Do, Mt. Sudo-san, 1,000 m, 1.VIII.1977, K. Yamagishi leg. (in KUC). Paratypes: same data, 14 males (in KUC).

Description. Male.

Head. Palp and other mouthparts yellow, face yellowish, posterior parts of head brown. Antenna brownish, scape, pedicel and base of $1^{\text {st }}$ flagellomere lighter. $1^{\text {st }}$ flagellomere about $4 \times, 2^{\text {nd }}$ $2 \times$ as long as wide.

Thorax. Pronotum yellow, with 3 longer setae. Mesoscutum brownish to brown, anterior margin widely yellow. Mesanepisternum and mesokatepisternum yellow. Scutellum yellow, with 4 long setae. Laterotergite yellowish to brownish. Mediotergite yellowish, posterior part brownish, bare.

Wing. Length 2.9-3.3 mm. Hyaline. Sc ending in R1 slightly distally or proximally to middle of small cell, Sc1 missing. Apical part of Sc bearing 6-13 macrotrichia. Small cell 1-1.5 times as long as wide. $\mathrm{Cu}$ fork distinctly distal to $\mathrm{M}$ fork. $\mathrm{M}$ ratios: $1.04-1.19,1.36-1.60$. $\mathrm{Cu}$ ratios: 1.00 1.05, 1.67-1.70. Macrotrichia: M petiole: 0; M1: 0; M2: 0; Cu petiole: 0; Cu1: 0; Cu2: 0. Halter pale yellowish.

Legs. Coxae and femora yellow, tibiae and tarsi brownish to brown. Coxa 1 without special setae. Coxa 2 without spur. Leg ratios: bt1:t1 = $0.69-0.79$, bt $2: \mathrm{t} 2=0.57-0.60$, bt $3: \mathrm{t} 3=0.56$ 0.57 .

Abdomen. Brownish.

Hypopygium (Fig. 3). Yellow. Tergite 9 with two pairs of combs, outer combs wide, both with about dozen spines, base of the comb with long, 

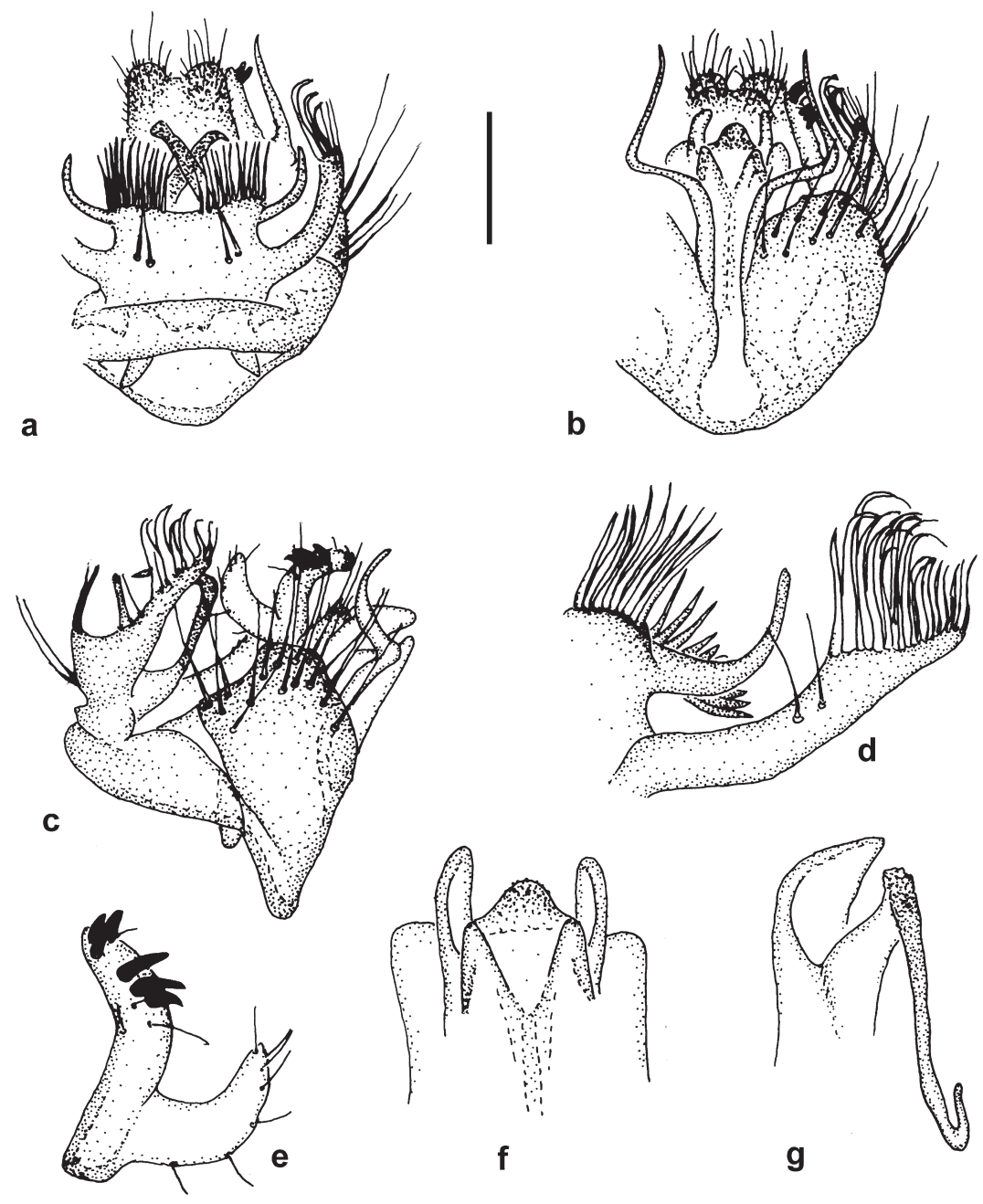

Fig. 3. Mycomya sudosanensis sp. n., male hypopygium. $-\mathrm{a}-\mathrm{c}$. Tergal, sternal and lateral views. $-d$. Tergal lateral appendage and tergal combs, with curved lateral extension at base of outer comb. - e. Gonostylus, twice enlarged. - f-g. Apex of aedeagus, sternal and lateral views, twice enlarged. Scale bar 0.2 $\mathrm{mm}$.

curved lateral extension (Fig. 3a,d). Tergal lateral appendage long, slender, slightly curved, mostly bare with a dense group of flattened curved apical setae (Fig. 3d). Sternal submedian filament long, curved. Gonostylus with 5-6 subapical teeth (Fig. 3e). Apex of aedeagus wide with lobes and poorly visible long curved spurs (Fig. $3 f-g$ ).

Female. Unknown.

Distribution. South Korea.

Etymology. The species is named after its type locality.

Remarks. Differs from the other species of the subgenus Mycomyopsis in the details of male hypopygium, e.g. in the shape and setosity of tergal lateral appendage and in having the characteristic long, curved lateral extensions of the base of the outer tergal combs. Nearctic M. dentata (Fisher,
1937) has similar lateral extensions of the base of the outer tergal combs, but it differs from $M$. sudosanensis sp. $\mathbf{n}$. in the shape and setosity of the tergal lateral appendage and gonostylus having 3 teeth.

Acknowledgements. I wish to thank Prof. Toyohei Saigusa and Prof. Hiroshi Shima (Ropponmatsu, Japan), for placing their material at my disposal. I am very grateful to Prof. Kari Heliövaara (University of Helsinki), Dr. Pekka Vilkamaa (Zoological Museum, University of Helsinki) and Jevgeni Jakovlev (Finnish Environment Institute, Helsinki) for technical assistance.

\section{References}

Colless, D. H. \& Liepa, Z. 1973: Superfamily Mycetophiloidea. Family Mycetophilidae (Fungivoridae). - In: Delfinado, M. D. \& Hardy, D. E. (eds.), A catalog of 
the Diptera of the Oriental region. Volume I. Suborder Nematocera: 444-463. The University Press of Hawaii, Honolulu. 618 pp.

Dziedzicki, H. 1885: Przyczynek do fauny owadów dwuskrzyglych. Rodzaje nowe: Hertwigia, nov. gen.; Eurycera, nov. gen. I Gatunki rodzajów: Boletina, Sciophila. — Pamietnik Fizyjograficzny 5(3): 164194. [In Polish.]

Edwards, F. W. 1935: Schwedisch-chinensische wissenschaftliche Expedition nach den nordwestlichen Provinzen Chinas, unter Leitung von Dr. Sven Hedin und Prof. Su Ping-Chang. Insekten gesammelt von schwedischen Artz der Expedition Dr. David Hummel 1927-1930. 49. Diptera. 15. Fam. Mycetophilidae, Bibionidae und Culicidae. - Arkiv för Zoologi 27 A, 30: $1-3$.

Fisher, E. G. 1937: New North American fungus gnats (Mycetophilidae). - Journal of the New York Entomological Society 45: 387-401.

Jakovlev, J. 2011: Fungus gnats (Diptera:Sciaroidea) associated with dead wood and wood growing fungi: new rearing data from Finland and Russian Karelia and general analysis of known larval microhabitats in Europe. - Entomologica Fennica 22: 157-189.

Krzeminska, E. \& Klimont, A. 2011: A new species of Mycomya from Siberia (Diptera: Mycetophilidae). Acta zoologica cracoviensia 54 B (1-2): 17-21.

Laštovka, P. \& Matile, L. 1974: Mycetophildae (Diptera) de Mongolie. - Acta Zoologica Academiae Scientiarum Hungaricae 20 (1-2): 93-135.

Okada, I. 1940: Die Fungivoriden-Fauna von Honschu (Diptera, Nematocera). — Tenthredo, Kyoto 3(1): 24 44.

Rondani, C. 1856: Dipterologiae Italicae Prodromus. Parma. 226 pp. [In Latin.]

Sasakawa, M.1961: Japanese Fungivoridae. I. Records of eleven unknown species from Japan. - Kontyu 29: 88-90.

Sasakawa, M. 2003: Notes on the Japanese Diptera. Part 2. - Japanese Journal of Entomology (New Series) 6(3): 119-133.

Sasakawa, M. 2005. (Fungus gnats, lauxaniid and agromyzid flies (Diptera) of the Imperial Place, the Akasaka Imperial Gardens and the Tokiwamatsu Imperial Villa, Tokyo). - Memoirs of the National Science Museum, Tokyo 39: 273-312. [In Japanese.]

Shinji, O. 1939: (On some unrecorded genera of Fungivoridae found in Japan). — Insect World, Gifu 43(1): 26, (2): 2-6. [In Japanese.]

Väisänen, R. 1984a: A monograph of the genus Mycomya Rondani in the Holarctic region (Diptera, Mycetophilidae). - Acta Zoologica Fennica 177: 1-346.
Väisänen, R. 1984b: Mycomya elephas sp. n. from California, and records of other Holarctic species (Diptera, Mycetophilidae). - Annales Entomologici Fennici 50: 115-117.

Väisänen, R. 1996: New Mycomya species from the Himalayas (Diptera, Mycetophilidae): 1. Subgenus $\mathrm{Myco}$ mya s. str. — Entomologica Fennica 7: 99-132.

Winnertz, J. 1863: Beitrag zu einer Monografie der Pilzmücken. — Verhandlungen der Zoologisch-Botanischen Gesellschaft in Wien 13: 637-964.

Wu, H. 1995: (Diptera: Mycetophilidae). — In: Wu, H. (ed.), Insects of Baishanzu Mountain, Eastern China: 435-450. China Forestry Publishing House, Beijing. 586 pp. [In Chinese.]

Wu, H. 1998: (Three new species of Mycomya from Longwangshan Nature Reserve of Zhejiang [Diptera: Mycetophilidae]). - Journal of the Zhejiang Forestry College 15(2): 170-175. [In Chinese.]

Wu, H. \& Yang, C. 1990: (Two new species of mycetophilids (Diptera: Mycetophilidae) from Nei Mongol). Entomotaxonomia 12(3-4): 275-278. [In Chinese.]

Wu, H. \& Yang, C. 1992: (The mycetophilids of Mt. Mogan with descriptions of 10 new species [Diptera: Mycetophilidae]). - Journal of the Zhejiang Forestry College 9: 424-438. [In Chinese.]

Wu, H. \& Yang, D. 1994a: The Chinese Mycomya (Diptera, Mycetophilidae). - Japanese Journal of Entomology 62: 65-77.

Wu, H. \& Yang, C. 1994b: (Three new species of genus Mycomya from Gansu [Diptera: Mycetophilidae]). Journal of the Zhejiang Forestry College 11(2): 165 170. [In Chinese.]

Wu, H. \& Yang, C. 1995a: A new species of the genus Mycomya from Sichuan Province, China (Diptera: Mycetophilidae). - Acta Zootaxonomica Sinica 20: 232233.

Wu, H. \& Yang, C. 1995b: Two new species of Mycomya (Diptera: Mycetophilidae) from Shanxi Province, Northern China. - Entomotaxonomia 17: 47-50.

Wu, H. \& Yang, C. 1996: A new species of Mycomya Rondani from Beijing (Diptera: Mycetophilidae) - Acta Entomologica Sinica 39: 310-311.

Wu, H., Zheng, L. \& Xu, H. 2001: Three new species of Mycomya in China (Diptera: Mycetophilidae). - Acta Zootaxonomica Sinica 26(4): 569-572.

Zaitzev, A. I. 1994: (Fungus gnats [Diptera, Mycetophiloidea] of Russia and adjacent countries. Part I. Families Ditomyiidae, Bolitophilidae, Diadocidiidae, Keroplatidae, Mycetophilidae (subfamilies Mycomyinae, Sciophilinae, Gnoristinae, Allactoneurinae, Leiinae). — Nauka. Moscow. 288 pp. [In Russian.] 